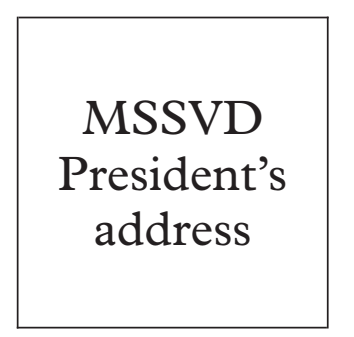

\section{Cinderella and the glass slipper: the growth and modernisation of a specialty}

\author{
Michael W Adler
}

Department of Sexually Transmitted Diseases, Royal Free and University College Medical School,

Mortimer Market Centre, off Capper Street, London

WC1E 6AU

$\mathrm{M}$ W Adler

Accepted for publication 2 November 1999

\section{Introduction}

The theme of my presidential address struck me as I was writing Jonathan Mann's obituary, in which I said that "so often when people retire or die their contribution to public life is soon forgotten." ${ }^{1}$ Even though I suggested that he was an exception to this generality, the basic point of the forgetting or lack of knowledge of history or individuals who have made significant contributions is brought home to me by the fact that the younger members of the Medical Society for the Study of Venereal Diseases (MSSVD) often have no sense of the history of the specialty of genitourinary medicine and, in particular, the colossal and rapid changes that have occurred over the past two decades. This lecture is devoted to these developments and concentrates on the tremendous changes which have occurred, particularly in the past 20 years, in relation to the disease profile, workload, and staffing within clinics, and growth in teaching, research, and, most recently, our programme of governance through national guidelines.

\section{History development/growth}

A clinical service was created following the Royal Commission on Venereal Diseases in $1916 .^{23}$ The next important step in the creation of a comprehensive service came in 1948 with the birth of the NHS and the clinics, which previously had usually been run by local authorities, being brought into hospitals. In 1948 we were a "Cinderella" specialty in terms of facilities, staff, and breadth of the diseases seen; they were predominantly syphilis and gonorrhoea, making up the majority of the 132000 cases that were diagnosed in clinics in England and Wales that year. At that time there was no specialist training in the subject which was called venereology. Senior staff had often come into this branch of medicine, not out of first choice, but because they had been responsible for the care of patients with venereal diseases in the armed forces and back in civilian life this had allowed for promotion without necessarily having a higher qualification.

Since the 1960 s there has been a very rapid increase in the number of cases seen in England and Wales (table 1) with a $108 \%$ rise in cases from 1960 to 1970, and a further 74\% from 1970-80 and a total increase of cases from 1960 to 1997 of over $600 \%$. As well as this increase the disease profile has changed. The "traditional diseases," particularly gonorrhoea and syphilis, have declined fourfold or $75 \%$ and $71 \%$ respectively. In contrast with the decline in these two traditional venereal diseases, which now represent less than $2 \%$ of all cases seen, we have witnessed the new viral diseases making an entry, in particular genital warts and herpes, with increases between 1980 and 1997 of $233 \%$ and $153 \%$ respectively.

The other remarkable change that has occurred is in the case mix of conditions managed. So even though the number of cases of AIDS and HIV may be considered to be small, the amount of counselling and testing carried out in clinics is substantial. Added to this, our increasing commitment to hepatitis B vaccination, family planning, cervical cytology, and sexual dysfunction represents an increasing workload for us. This widened disease profile and case mix represents the modern era of our specialty.

\section{Facilities/staffing}

Having indicated the colossal increase in workload, how have the facilities in terms of clinics and staffing kept up? Three important developments in the 1980s drove the modernisation and increase in clinic facilities and staffing. Firstly, there was the setting up of the Royal College of Physicians specialist committee in genitourinary medicine in 1984 chaired by Duncan Catterall. Secondly, the acknowledgment by the Department of Health, and, in particular, David Mellor in his executive letter of 1986, that ring fenced money for AIDS services could be used for GUM clinics, and thirdly the Monks report of $1988 .{ }^{4}$ The report made a series of recommendations about the need for the service to be designated as a clinical and political priority, with additional resources for clinics in each district.

Even though these three initiatives of the college committee, the Mellor letter, and the Monks report were important in pushing the specialty forward, ultimately what was also required was an increase in staffing levels. It wasn't until 1985 when the college committee, then with me as chairman and George Kinghorn as secretary, carried out the specialty's first staff level survey so that we were able to get a more accurate idea of the numbers of consultants, their age, and the qualifications of senior staff and those in training and estimate

Table 1 New attendances at genitourinary medicine clinics 1960-97

\begin{tabular}{llll}
\hline Year & Attendances & $\begin{array}{l}\text { \% Increase per } \\
\text { decade }\end{array}$ & $\begin{array}{l}\text { \% Total increase } \\
(1960 \text { base year })\end{array}$ \\
\hline 1960 & 129506 & - & - \\
1970 & 269180 & 108 & 108 \\
1980 & 469140 & 74 & 262 \\
1990 & 595848 & 27 & 360 \\
1997 & 989735 & 66 & 664 \\
\hline
\end{tabular}




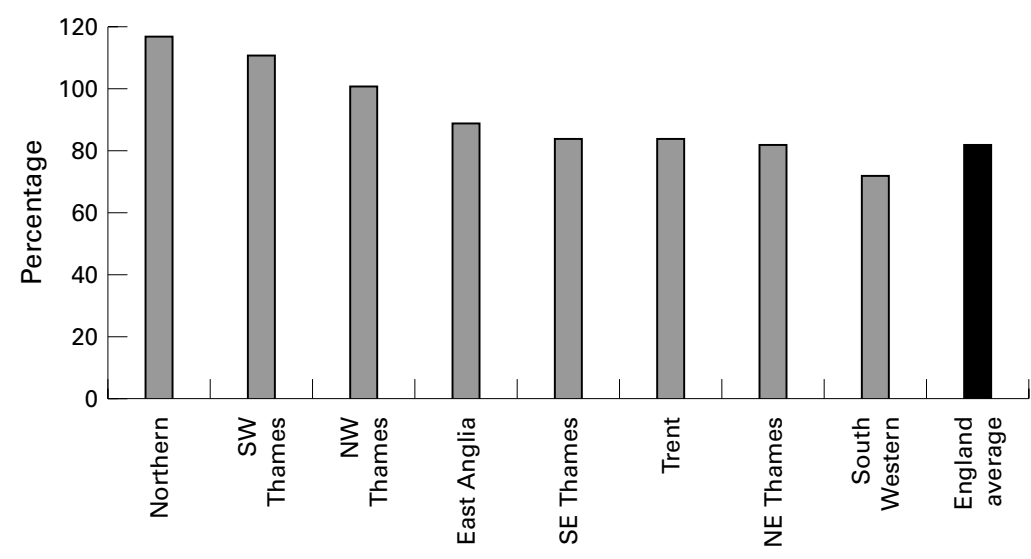

Figure 1 Staff shortfall. Percentage increase in sessions required per week—top eight.

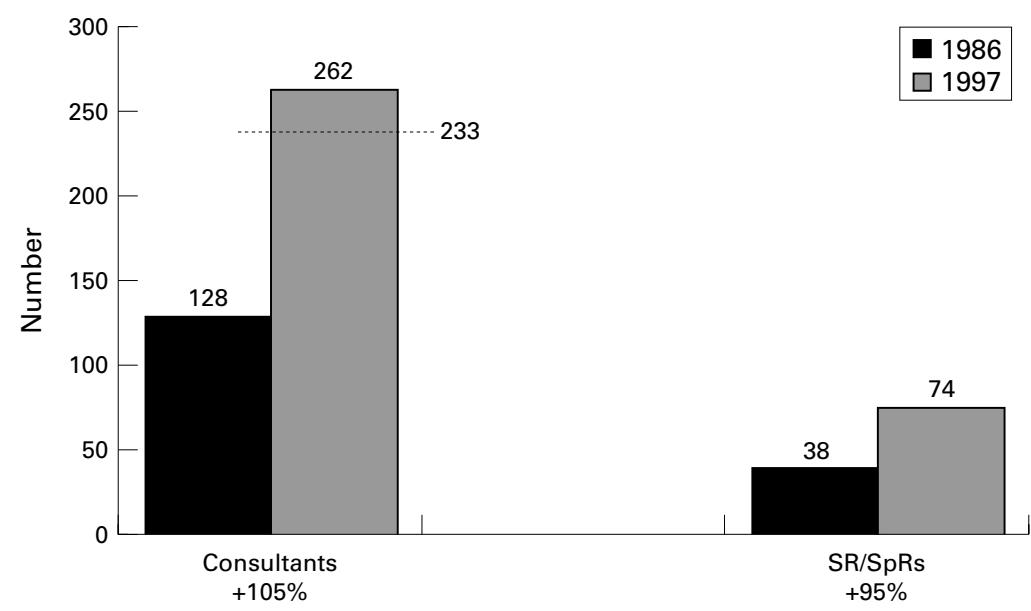

Figure 2 Expansion in number of consultants and senior registrars (SR)/specialist registrars (SpRs), 1986-1997, United Kingdom.

the future staffing requirements for the specialty. To obtain this requirement we devised a formula that was based on the notion that to achieve an acceptable standard, each patient consultation has a minimum requirement of doctor time. Not surprisingly we came up with data which suggested that there were large staff shortfalls throughout England and Wales, and used this to give evidence in 1988/9 to the Joint Planning Advisory Committee (JPAC), the committee that was responsible for staff level planning for all specialties.

The greatest shortfall in terms of percentage of increase in sessions that would be required per week was shown in the Northern and Thames regions. For England, the total average of staff level shortfall was $82 \%$ (fig 1 ). We argued with the JPAC that the number of consultant posts over a 10 year period from 1986-95 needed to increase by $82 \%$ - that is, from 128 to 233 and that 56 senior registrars in training were needed to meet this requirement.
This was an extremely successful exercise which set us on our way, and we expanded past our target of 233 or $82 \%$ to 262 , a $105 \%$ rise. We also achieved a similar increase in training posts (fig 2).

Finally, in relation to this work which the college committee carried out, it is interesting to see the higher qualifications held both by consultants and senior registrars in 1985 compared with the most recent data for 1998 (table 2 ). From this it can be seen that $38 \%$ of consultants working in the specialty in 1985 did not have an appropriate higher qualification recognised by the Joint Committee on Higher Medical Training (JCHMT). The only encouragement that we could get from the 1985 survey was that the senior registrars were better qualified than their consultants; $38 \%$ of consultants, but only $16 \%$ of senior registrars did not possess a suitable higher qualification. This has changed, and it would now be totally impossible to get a consultant post or to be appointed as a specialist registrar without a higher qualification. The latest available data (1998) show that all senior registrars/specialist registrars have a higher qualification and that compared with 1985, only just under $9 \%$ of consultants appear not to have a suitable higher qualification compared with the very substantial $38 \%$ in 1985.

The number of consultants without qualifications in 1985 says something about the specialty and the fact that even at that time people were coming into it not necessarily out of first choice and because it was possible to obtain a consultant post without an appropriate higher qualification. One of the things that delights me particularly about the consultants and trainees today is that most of them have decided that genitourinary medicine is an exciting and fulfilling specialty and have chosen it as their first option.

So much for our own backslapping and internal developments, but what about national external validation? The criteria for this are of course not available, but a surrogate would be to look at distinction awards, and how these have changed over time for consultants in the specialty (fig 3).

In 1980 we had no A+ awards, the national average for these awards for all specialties was $1 \%$; for As we had 2-namely, $1.9 \%$ which again was below the national average at $2.8 \%$; and for Bs we had 8-namely, 7.4\% which again was also below the national average of $9.6 \%$. If we now compare this with 1998 , even though the number of awards has increased as one would expect with a doubling in the

Table 2 Higher qualifications consultants/senior registrars (SRs)/specialist registrars (SpRs) 1985 compared with 1998, United Kingdom

\begin{tabular}{|c|c|c|c|c|c|c|c|c|}
\hline \multicolumn{5}{|l|}{1985} & \multicolumn{4}{|l|}{1998} \\
\hline \multirow[b]{2}{*}{ Qualifications } & \multicolumn{2}{|c|}{ Consultants $(n=136)$} & \multicolumn{2}{|c|}{ SRs $(n=38)$} & \multirow[b]{2}{*}{ Qualifications } & \multirow{2}{*}{$\begin{array}{l}\text { Consultants } \\
(n=262)\end{array}$} & \multirow{2}{*}{\multicolumn{2}{|c|}{$S R s / S p R s(n=74)$}} \\
\hline & No & $\%$ & No & $\%$ & & & & \\
\hline MRCP & 43 & 31.6 & 18 & 47.5 & 150 & 57.3 & 61 & 82.5 \\
\hline MRCOG & 36 & 24.5 & 13 & 34.2 & 60 & 22.9 & 13 & 27.5 \\
\hline FRCS & 3 & 2.2 & 1 & 2.6 & 4 & 1.5 & - & \\
\hline Other & 52 & 38.2 & 6 & 15.8 & 23 & 8.7 & - & \\
\hline No information & 2 & 1.5 & - & & 25 & 9.6 & - & \\
\hline
\end{tabular}




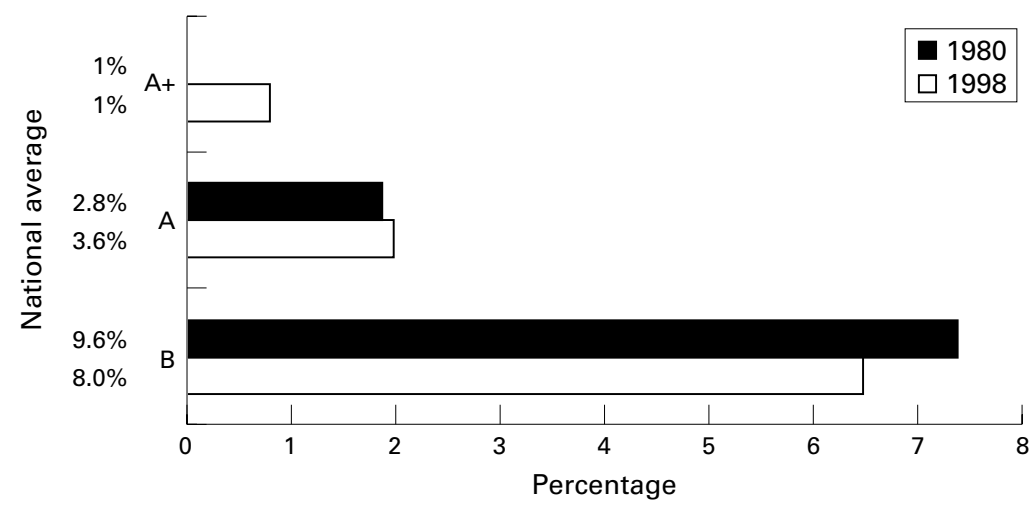

Figure 3 Distinction awards in genitourinary medicine 1980 and 1998.

consultant workforce, apart from the A+ awards where we now have 2 (still below the national average), there has been little change in the As and a decline in the Bs from $7.4 \%$ to $6.5 \%$. Clearly this is disappointing at one level, but it has to be remembered that the total number of consultants has increased at such a rate that inevitably there will be a much larger number of younger consultants appointed which means that it will be some time before they get through the system to be eligible for higher awards. This is a criterion of our advancement that we need to return and look at in about 10 years' time. How do we compare with other specialties? Table 3 shows the lowest and highest five specialties in terms of distinction awards ( $\mathrm{A}+$ to $\mathrm{B}$ inclusive) compared with genitourinary medicine. Respiratory medicine is top with $34 \%$ of consultants holding awards, and the lowest is palliative medicine, with $5 \%$. We are near the bottom of the league with $9.4 \%$.

\section{Research}

I would now like to look at research within the specialty. Even though formal academic departments have only been created over the past two decades, genitourinary medicine has a long tradition of scientific inquiry, particularly exemplified by the MSSVD which is now 77 years old.

The first chair, my own, was created in 1979 at the Middlesex Hospital Medical School, and was followed subsequently by chairs at St Mary's (1991), Liverpool (1994), and most recently King's (1999). In addition, there have been smaller academic units at Southampton, St Thomas's, and St George's. The creation of formal academic departments over the past 20

Table 3 Proportion of consultants holding $A+$ to $B$ inclusive distinction awards - top and lowest five specialties (above 100), 1998, England and Wales

\begin{tabular}{lrr}
\hline & $N o$ & $\%$ \\
\hline Respiratory medicine & 188 & 34.6 \\
Endocrinology/diabetes & 172 & 33.7 \\
Gastroenterology & 200 & 29.5 \\
Medical oncology & 129 & 27.9 \\
Renal medicine & 169 & 25.4 \\
Learning disability & 204 & 7.4 \\
Child and adolescent psychiatry & 479 & 7.3 \\
Accident and emergency & 415 & 7.0 \\
Anaesthetics & 3099 & 6.4 \\
Palliative medicine & 103 & 4.9 \\
Genitourinary medicine & 245 & 9.4 \\
\hline
\end{tabular}

years has changed the ethos, culture, and attitude towards research within the specialty and helped to raise the profile of the society and genitourinary medicine, so that we are now viewed as any other major specialty in our scientific and training standards. In addition, the academic units have made contributions regularly to international scientific meetings, and I think that it is now seen that the United Kingdom has a very active broad based research programme and profile both in sexually transmitted diseases and HIV/AIDS.

\section{Teaching-undergraduate}

I would now like to look at teaching within the specialty, and start with undergraduate teaching. I obviously don't need to stress the importance of undergraduate training in our specialty since so many aspects of the diseases and sexual health reach into every other area of medicine. But also, of course, teaching is important if for no other reason than that it exposes the undergraduate to our specialty, and is potentially a way of stimulating interest and recruiting young doctors into genitourinary medicine. A number of surveys have been carried out into the teaching of genitourinary medicine in British medical schools. The first of these, by Webster in 1966, looked at the training in the specialty covering 439 out of 709 of the world's medical schools. ${ }^{5}$ The mean teaching time for all participating schools was 42.7 hours, and for the United Kingdom was much lower at 19.2 hours. It wasn't until 1981 that Dick Wilcox and I carried out the first detailed survey of undergraduate training in Britain. We found that the total mean teaching time (lectures and clinical attachments combined) was 15 hours. $^{6}$ This represented a reduction in teaching hours since the survey carried out by Webster in 1966.

In 1984 I carried out a postal survey to see whether there had been any difference from the previous survey of 1980 and showed a small increase of 1.4 hours in total teaching time between the two surveys. ${ }^{7}$ In 1994, Frances Cowan and I carried out a further and fuller survey. ${ }^{8}$ We found that the average time allocated for lecturing and clinical teaching of the specialty had decreased since 1984 to a mean of 15.1 hours although there was considerable variation between schools.

\section{Postgraduate training/CME and the MSSVD}

The slow development of undergraduate teaching is depressing; however, it is in sharp contrast with our achievements in relation to postgraduate training and continuing medical education. I think in this latter area we have, as a specialty, made great strides over the past 20 years. I think the reason that we have been able to do this, in contrast with undergraduate education, is that we have had more control over what it is that we wish to do, and have therefore been in the driving seat through the MSSVD. And I would now like to look in more detail at the role of the MSSVD in education.

I have already mentioned the importance of our ordinary general and spring meetings, but 
added to this, the MSSVD has instigated some major developments over the past few years, and I will start with the education subcommittee.

THE EDUCATION SUBCOMMITTEE

This was set up in 1993 when it was recognised that more thought needed to be given to our educational role and that it was not always possible for this to be done by council given its already busy agenda. The education subcommittee was set up to consider the annual scientific programme, selection of papers for the spring meeting, undergraduate training, postgraduate training including $\mathrm{CME}$, judging of oral/poster presentations for spring meeting, undergraduate and junior doctors prizes.

At approximately the same time it was felt that the society's educational interest could also be well served by creating special interest groups around particular subjects, and the first two groups were the HSV and HIV special interest groups. The groups were encouraged to fulfil their role by setting up special meetings and also developing protocols if necessary and collaborative research projects. The original two groups have now been expanded to five with the inclusion of groups for sexual dysfunction, human papillomavirus, and bacterial infections. The chairs of these groups are now members of the education subcommittee. The final group to mention, but in fact the very first one, is the British Clinical Co-operative Group, which was founded in 1951.

When I became president in 1997, I was keen that the MSSVD should have a clearly defined role in terms of education. I felt that our educational responsibilities should be widened if we were going to see that genitourinary medicine impinged on undergraduates and postgraduates, both those specialising in our field and those who are not. I have identified four areas for us to concentrate on and which I have tried to push forward as president.

\section{Undergraduate teaching}

The first area that we need to look at is undergraduate teaching. As I indicated earlier, we have over the years carried out a number of surveys on undergraduate education. It seems to me that we could of course continue to reassess the amount of teaching time in the specialty, but more importantly we needed to move on and look at how teachers in different undergraduate schools could share innovative ideas and teaching materials; the ways in which we could more readily encourage undergraduates to come in to the specialty, not only through their exposure to our teaching, but through other ways such as career fairs, scholarships, short attachments, etc.

Non-consultant career grades

The next area I am keen to look at is non-consultant career grades. Someone once described this group as "the lost tribe of the specialty" and many of us felt that the group needed to have a standard period of induction covering core skills and, secondly, we needed to address their ongoing CME. Since this group is often not able to get to departmental or national meetings, it might benefit from packages of distance learning, special courses, etc.

\section{General professional training for $\mathrm{SHO}$}

The third area we need to cover is in relation to general professional training for senior house officers. Even though the specialty has an entry in the core curriculum handbook published by the Royal College of Physicians, I feel that we need to expand and to think of ways in which SHOs can learn more about our specialty.

\section{CME for those specialising in genitourinary medicine}

The final and particular area of interest to this audience is our own CME as specialists. As I indicated earlier, the educational needs of those in the specialty have mostly been met by our own scientific meetings generated by the MSSVD, and more recently also added to by the special interest groups. I am keen that we examine this whole field of CME and how we roll out education into the regions, how this could be best achieved, and what innovative educational techniques and technologies would help to facilitate this more readily.

Again, it seems to me that if the MSSVD wishes to take on a wider educational remit, which I feel is important for our own academic vitality, we need to put more time and commitment into this important initiative. Council is keen to push ahead with this, and I think probably the most significant recent development for the society has been the appointment of an education officer. The first holder of this post is Dr Jonathan Cartledge. Following his appointment, the council decided that if this initiative was going to be effective, Jonathan would need support, and we have decided therefore to fund a full time educational coordinator.

Obviously the programme I have outlined is far too broad and we can't possibly get involved in all of these areas at once, but we have already developed a consensus document for undergraduate teaching. This covers the essential topics in genitourinary medicine that should be included in the undergraduate core curriculum of all medical school and which has now been circulated to schools. In that document we put emphasis on the fact that no other specialty deals so specifically with sexuality, and that students should be encouraged to develop non-judgmental approaches towards patients with sexually transmitted diseases and sexual health problems. We have also carried out needs assessments of the educational requirements and induction training of all genitourinary medicine doctors in the United Kingdom. Future priorities are in relation to induction programmes, chlamydia screening, training for general practitioners, how to plan one's CME/ CPD course, courses for teachers and undergraduate teaching materials, career fairs materials, and the development of a lecture library.

The other important development around education have been driven by the Specialist Advisory Committee (SAC) which is, as you know, independent of the MSSVD, but does 
have representation from the society. In the past few years the SAC has developed a very full and detailed curriculum which has to be followed by specialist registrars. The plans of the MSSVD have been added to this, and I hope you will agree are complementary.

The final development which can be used for educational purposes was the setting up of our own website which, as well as giving information about the society and its functions will in the future be used for both education of those working in the specialty and, possibly, for education of the general public who would want to $\log$ on for specific information; for example, currently we are thinking about this in relation to chlamydial infection.

\section{MEMBERSHIP OF THE MSSVD}

Since the creation of the MSSVD in 1922 the number of members has increased considerably, but as you also realise, membership was virtually exclusively made up from the medical profession. You will also be aware that in the past year we have made attempts to widen the membership of the society in recognition of the fact that it is a multidisciplinary specialty with very significant contributions being made from laboratory scientists, epidemiologists, sociologists, health advisers, and nurses. I think this widening will add a new dimension to the society, its role, and also its health. In recognition of this, this year's council elections had two places put aside for representatives of nonconsultant career grades and general practitioners, and, secondly, a representative of other healthcare workers in the specialty.

\section{AUDIT/GUIDELINES}

Finally, I would like to turn to the specialty's initiatives in relation to audit and the development of guidelines. The specialty has a long tradition of self appraisal which started with the setting up of the British Clinical Cooperative Group in 1951.

The group tended to concentrate on specific disease areas and as far as I can see, it wasn't until 1976/7 that the first survey of all clinics was carried out to collect information on the diagnostic and reporting criteria used in clinics in England and Wales, and to compare treatment and management policies. ${ }^{9}$ This study showed a lack of universal standards and accepted criteria for the diagnosis and management of most diseases.

This work illustrated to me the need for audit and national consensus among clinicians. My survey and the cooperative group's work represented the specialty's first attempt at audit and governance, which has greatly expanded over the past 20 years, culminating in the development of national guidelines for the management of various diseases. The recent history of these developments started in 1990 with the formation of a joint SAC/RCP working party on audit, chaired by David Barlow, which looked at audit activity and the support given to this within the specialty nationally. It was clear from this that there was continuing audit activity throughout the United Kingdom, but not coordination or standardisation. This lack of coordination led to the formation of the Central Audit Group chaired by Mark Fitzgerald, and major pieces of work on the management and contact tracing for gonorrhoea and subsequently on chlamydia. These important pieces of work were then followed by the creation of the Clinical Effectiveness Group in October 1997, jointly by the MSSVD and AGUM. The main work of the group, chaired by Dr Keith Radcliffe, has been the development of national guidelines for the management of various diseases. Once again, we are leading the field in that there are not many other specialties in the United Kingdom that have at this time produced their own specialty guidelines for management and care. I think we can congratulate ourselves, and particularly the people leading on the national guidelines who have produced excellent material.

I have spent this lecture looking at the recent past and, in particular, the expansion and modernisation of our specialty to a state where it stands at the forefront of clinical development, education, research, and audit. So let me spend the last few minutes contemplating how we got there, but more importantly, where we might be heading. This takes me to the title of my talk, "Cinderella and the glass slipper: the growth and modernisation of a specialty." In my view, the glass slipper which allowed for this growth and modernisation was the ring fenced AIDS money and the political manoeuvring by some consultants in the specialty to persuade the government that the network of genitourinary medicine clinics formed the backbone of good HIV as well as STD control and that existing structures needed to be modernised. It was a crucial political opportunity for us, which we grabbed.

So having fitted the slipper to the foot, we sit in the glass coach; but of course we all remember that eventually this changed into a pumpkin. It is vital that this does not happen to us as a specialty, but it could if we rest on our laurels and unless we face the future threats and opportunities and define where we are going.

There are a number of questions that we need to think about - for example, what is the role and place of the specialty in delivering sexual health? How should we help in the definition of a national sexual health strategy? How are we going to tackle unmet demand in the community? On our own or with Primary Care Groups (PCGs) and family planning clinics? How can we ensure the future funding of genitourinary medicine as residence based funding for HIV/AIDS comes in and cross subsidies will probably be less? These are some of many questions. I firmly believe that unless we tackle these very difficult issues, and are involved in defining a national sexual health strategy, we will turn into pumpkins. The next few years are crucial in defining our role and future, a future built on good foundations laid down over the past two decades. It is no good looking to others for a definition of our future, and I believe that it is dangerous to do so since it will not be what we want, need or, in 
particular, is right for the control of STDs and HIV. We have to define and shape our own destiny, and having done this, will probably find that politicians and others will be grateful for a group who have a clear idea of where they want to go, and will, if anything, help and facilitate this. The real danger is our own internal inertia, self satisfaction, and inclination to think we have done well enough and to look over our shoulders hoping that someone else will solve our problems. Dorothy Parker was once asked the meaning and definition of "horticulture" and replied, "You can lead a whore to culture but you cannot make her think." As a specialty, we need to keep thinking and defining our role. The government's desire to create a national strategy for HIV and sexual health is our next political opportunity to create the type of specialty we want to take us into the next century, and fend off some of the threats to us as the natural group to provide leadership in this area of medicine. The energy and commitment for this task have to come from the new generation, to which most of you belong. I have the greatest confidence that you will make sure that the glass coach rides on uninterrupted.

Presidential lecture MSSVD delivered 21 May 1999.

1 Adler M. Jonathan Mann. (Obituary) Sex Trans Inf 1998;74:390.

Royal Commission on Venereal Disease. Final report of the commissioners. London: HMSO, 1916 (CMMD 8189).

3 Adler MW. The terrible peril-a historical perspective on the venereal diseases. BMF 1980;281:206-11.

4 Department of Health. Report of the working group to examine workloads in genitourinary medicine clinics. London: Department of Health, 1988

5 Webster B. Teaching of venereal diseases in medical schools throughout the world. Br F Vener Dis 1966;42:132-3.

6 Adler MW, Wilcox RR. Teaching of genitourinary medicine (venereology) to undergraduate medical students in Britain. Br ₹ Vener Dis 1981;57:170-3.

7 Adler MW. Survey of medical undergraduate teaching in genitourinary medicine in Britain. Genitourin Med 1984;60: 405 .

8 Cowan FM, Adler MW. Survey of teaching in genitourinary medicine in Britain. Genitourin Med 1994;70:311-13.

9 Adler MW, Belsey EM, O'Connor BH, et al. Facilities and diagnostic criteria in sexually transmitted disease clinics in England and Wales. Br F Vener Dis 1978;59:2-9. 